\title{
Clinical Research Resources at The University of Kansas Medical Center: General Clinical Research Centers (GCRC) and Clinical Translation Science Awards (CTSA)
}

\author{
Richard Barohn
}

Professor and Chair, Neurology

The University of Kansas Medical Center

\begin{abstract}
7 he federally funded General Clinical Research Centers program (GCRC) has been in existence for nearly 50 years. What is a GCRC? It is a National Institutes of Health (NIH)-supported multidisciplinary research unit that facilitates investigator-initiated clinical studies and trials conducted by full-time faculty at an academic health center (AHC). GCRCs provide clinical research infrastructure to investigators who receive funding from federal agencies, private foundations, and other peer-reviewed sources. A GCRC can also provide support for investigator-initiated, unfunded pilot studies and, to a limited extent, for industrysponsored studies. The premise for usina an infrastructure on a GCRC is that the space,
\end{abstract}

the equipment, and personnel are provided at no cost for investigatorinitiated clinical research studies.

There are now approximately 80 $\mathrm{NIH}$ funded GCRC programs throughout the United States. These programs are funded through the National Center for Research Resources (NCRR) arm of the NIH. There are NIHfunded GCRCs at Washington University in St. Louis School of Medicine, St. Louis, Missouri; University of Iowa Health Care, Iowa City; and University of Oklahoma College of Medicine in Oklahoma City. Further information on the GCRC program through the NCRR can be found at their web site: www.ncrr.nih.gov.

\section{Development of a GCRC at the} University of Kansas Medical Center We began the process of initiating a GCRC for The University of Kansas Medical Center (KUMC) campus in 2002. At that time we established four goals:

- Provide clinical investigators from the School of Medicine, School of Nursing and School of Allied health with a modern, state of the art facility in which clinical research could be conducted.

- Enhance multidisciplinary research across departments and the three schools.

- Enable and train junior faculty and trainees to become more involved in clinical research. 
- To apply for federal funding to support the GCRC.

We have accomplished each of these goals. At the present time, though our GCRC is not yet federally funded, we have set up the infrastructure for a typical GCRC and are operating under the NCRR guidelines for funded GCRCs.

The typical organizational structure for a GCRC is outlined in Figure 1. The Executive Dean of the School of Medicine, Barbara Atkinson, MD, serves as the overall principal investigator for the GCRC and I serve as the Program Director. The GCRC at KU Medical Center currently is an exclusively outpatient GCRC unit. NIH-funded GCRCs often have fixed inpatient beds for overnight stays as part of the GCRC, or can accommodate overnight patients in the university hospital through a scatter-bed system. In our NIH grant proposal for funding for our GCRC (see below), we have adopted the scatter-bed model. The GCRC grant will then provide funds for our overnight inpatient stays for our investigatorinitiated trials. We do have a core laboratory on our GCRC for specimen processing, centrifugation, and temporary storage in a $-70 \mathrm{C}$ freezer. We can measure serum glucoses using an YSI instrument.

We also have a modern, fully functioning metabolic kitchen that can be utilized by investigators, primarily those in the Department of Nutrition. The Department of Bioinformatics provides study design and biostatistical and data management support.
The GCRC Advisory Committee (GAC)

A critical part of a functioning GCRC is a GCRC Advisory Committee (GAC). Investigators must submit their protocols to the GAC, which meets monthly. The GAC reviews all protocols for scientific content as well as for the need for utilization of the GCRC infrastructure. The GAC at The University of Kansas Medical Center is co-chaired by Matthew Mayo, PhD, and Jared Grantham, M.D. There are currently 20 voting members on the GAC, as well as a dozen ex officio members. One ex officio member serves as a research subject advocate (RSA) and reviews each protocol to ensure subject safety. This is an additional layer of safety review above and beyond that done by the human subjects committee (HSC). A research subject advocate is a mandatory component of all $\mathrm{NIH}$ funded GCRCs. There is also a biostatistician on the GAC who reviews each protocol for biostatistical research considerations. A GAC provides direct feedback to the investigators after the protocol is reviewed. Once a protocol is approved, the investigator can utilize the resources of the GCRC to perform the research.

\section{What can the GCRC do to facilitate clinical research?}

For GAC-approved studies, GCRC can:

1. Provide space to see patients.

2. Provide biostatistical support and study design.

3. Provide data management.

4. Provide nurse support.

5. Provide specimen collection and storage. 
6. Provide some equipment that can be used in common by multiple investigators.

7. Provide some laboratory studies that can be performed on the GCRC or they can be performed at another laboratory which GCRC funds. As mentioned above, there is no cost to the investigator for the services for investigator-initiated studies. If a clinical research study is initiated by industry, and is being performed by a local investigator, there is a charge for the GCRC space and resources.

There are some services the GCRC cannot provide. We cannot provide research coordinators to investigators for their clinical research studies. The investigators must cover these costs through their grant funding. Under current NIH guidelines, the GCRC cannot provide significant resources for industry-initiated clinical research. Only approximately $10 \%$ to $15 \%$ of all protocols performed in an NIH-funded GCRC can be initiated and sponsored by industry. While the GCRC charges the industry grant for space and resources, under current guidelines, only $\$ 25,000$ annually can be received by a GCRC for these projects. Any amounts received over that level will result in a decrease in funds provided by the NIH/NCRR grant.

Currently the GCRC is located in approximately 6000 square feet of newly remodeled space on the ground floor of the Delp Pavilion at The University of Kansas Medical Center. There are six patient examination rooms; a large infusion / procedure area; a specimen processing laboratory; cognitive testing room; patient lounge; exercise physiology suite with a metabolic cart; metabolic kitchen; computer laboratory; conference room for our GCRC and other clinical research related meeting; and administrative rooms for the biostatistician, nursing and administrative personnel, the program director, and associate and assistant program directors.

\section{The GCRC Timeline at KUMC}

A GCRC planning committee was formed in 2002. This committee met monthly for two years in order to develop the infrastructure needs for the GCRC. The space in the Delp Pavilion was identifie; remodeling began in June 2004 and was completed October 2004. Doctors Atkinson and Barohn announced the formation of the GAC in the summer of 2004 and notice went out to all clinical investigators on the KU Medical Center Campus to indicate that research applications could be submitted. The GAC began reviewing protocols in September 2004.

The GCRC officially opened its doors in January 2005. The GAC continues to review protocols monthly and as of August 2005, there are currently 57 approved protocols. Simultaneous with the development of a functioning GCRC, a grant application was prepared. The NCRR had been notified of the development of our GCRC at KU Medical Center when we began the planning process in 2002 and they had scheduled us to submit our proposal in June 2006. The KU Medical Center GCRC NIH grant application was submitted on June 1, 2006, and is currently under review. 
Two primary sources have provided the funding for the KU Medical Center GCRC since its inception. The majority of the funds have been supplied through the executive vice chancellor office at KUMC. Funds were provided for renovation of space, office supplies and computers, and most significantly nursing, administrative and biostatistical personnel. In addition, The University of Kansas Hospital generously provided all initial equipment and medical supplies in the clinical research areas, including such equipment as a metabolic cart, electrocardiogram, freezers, centrifuges, and all one-time-use disposable medical supplies. All of this financial support was provided in anticipation of an $\mathrm{NIH}$ grant submission.

\section{CLINICAL TRANSLATIONAL SCIENCE AWARDS (CTSA)}

Barriers to Clinical Research

Despite the development of the successful NIH-sponsored GCRC program over the last 50 years, there are still considerable barriers to initiating and completing successful clinical research at academic health centers. Dr. Elias Zerhouni, director of the NIH, has outlined the challenges for clinical research. ${ }^{1}$ Dr. Zerhouni has pointed out that there has been an explosion in clinical demands with reduced financial margins so that clinicians have less time to devote to training as a clinical researcher, and then to ultimately perform clinical research studies. The training that is available is very fragmented for young researchers, is divided between multiple university components, and it is difficult for a young investigator or to attain the required training in an easily accessible fashion. There is an increased regulatory burden that provides another major barrier to clinical research. The regulatory burdens have become increasingly complex and time consuming and these mandates often prolong an already lengthy research trajectory. The resulting delay in generating results from clinical and translational studies additionally contributes to difficulties with promotion and tenure decisions for clinical investigators.

In summary, Dr. Zerhouni has stated that there is no true "HOME" for our clinical research. Based on this recognition, he has proposed a "systems biology approach" to creating a home for clinical and translational sciences.

\section{Announcement of the Clinical and}

Translational Science Award Program

In October 2005, the NIH released an RFA announcement for institutional Clinical and Translational Science Awards (CTSA). The stated purpose for the CTSA project was to forge a transformative and integrative academic home for clinical and translational science. Dr. Zerhouni has stipulated that these new homes in academic health centers must be a Center, Department, or Institute. These clinical research units must encompass all components of clinical research, including education, career development, and regulatory components for clinical research infrastructure. These new clinical research units must promote multidisciplinary research teams, create an incubator for innovative research tools, and catalyze the application of new 
knowledge to clinical practice. These clinical research units must also provide degree-granting capabilities in clinical research that will lead a trainee to either a Masters or a PhD degree.

With regard to the existing GCRC program, it is anticipated that existing funded GCRC programs will be slowly phased out. However, the clinical research infrastructure provided by GCRCs can be incorporated into the larger CTSA Awards. By doing so, this will give academic health centers greater flexibility in modeling clinical research infrastructure space for the future. In this new model, there will potentially be fewer restrictions on collaborations with industry in developing clinical research programs at academic health centers. For example, these appear to be no restriction on number of industry sponsored studies or in the amount of funds that a clinical research center can receive from industry.

Planning Process for the CTSA at KUMC and the Kansas City Region

Shortly after the RFA for the new CTSA Awards, a planning process was initiated at KU Medical Center to develop our university's response to this new program. The various planning committees and subcommittees were established in October 2005 (see Table 1) and began meeting regularly. The timeline of the RFA was that applications had to be submitted to the NIH by March 27, 2006. At that time, the $\mathrm{NIH}$ was accepting two types of applications. The first was a planning grant for $\$ 150,000$ that would allow academic health centers time and some resources to further develop a global
CTSA application. The second type of grant was a full CTSA application that could be as large as 6 million dollars per year (if pediatric clinical research was involved; up to 4 million dollars without clinical pediatric research). In addition to the 6 million dollar per year CTSA award, all existing K30, T32, and GCRC grants were to be rolled into the CTSA application. By doing so, a full CTSA application would become one of the largest institutional research grants that an academic health center could receive. The stated goal of the NIH was to fund 60 small CTSA planning grants and five to seven full CTSA grants in the first round of applications. Their ultimate goal is to fund 60 full CTSA awards throughout the United States by 2012.

As our planning committees met, we recognized there would be a number of weaknesses and strengths for KU Medical Center CTSA application. The weaknesses included:

- No current GCRC NIH funding.

- No clinical T32 training grants.

- Relatively small clinical mentors and mentors of current clinical R1 grants.

The strength of KU Medical Center CTSA application included:

1. The existing NIH funded K30 program and the Masters of Science and Clinical Research Program.

2. The current existing GCRC infrastructure.

3. The Research Institute at KU Medical Center.

4. The multidisciplinary and collaborative research efforts between the School of Medicine, School of Nursing and School of Allied Health.

5. A strong bioinformatics center. 
6. Strong ties with programs at the University of Kansas-Lawrence Campus, particularly drug development and the Lifespan Institute.

7. Potential strong ties with partners in the community, other regional academic centers and in private industry.

As a result of the CTSA planning process, it was decided to submit a CTSA planning grant before the March 2006 deadline. The planning grant has been submitted and is currently under review.

Our goal is to recruit a project manager and administrative assistant who will assist us in the CTSA planning committee process. All of the committees will meet regularly over the next year to determine the timing and content of KU Medical Center's full CTSA application.

\section{Concept of a Heartland Institute for Clinical Research}

Our CTSA planning grant application outlined the concept of a new Heartland Institute for Clinical Research (HICR) that will be a new integrated home for clinical and translational research, both at KU Medical Center and in the region. We anticipate that the HICR will consist of many centers, and within each center will be a number of cores or programs (see Figures 2 and 3). For example, within the education center there will be the existing Masters of Clinical Research and K30 programs and new additional K12 and T32 career development awards that can provide significant salary support and thus release time so that young investi-gators can pursue training in clinical research. The education center will also encompass developmental programs including the recently initiated Intro-duction to Clinical Research course that was launched in the fall of 2006 semester, as well as a proposed Research Coordinator Training Program that is under development. The current GCRC will be incorporated into a new Clinical Research Resource Center (CRRC). The CRRC will also include a Clinical Research Pilot Grant Program where a junior investigator can apply for up to $\$ 50,000$ seed funds for a new clinical research project. The CRRC will also contain a new protocol development/ assistance core to aid a new investigator in preparing a grant submission. Within the Novel Methodology and Translational Technologies Center will be cores that will house technologies to facilitate translational research. An investigator will be able to apply to the Novel Methodology and Translational Technologies Center for access to these individual cores for their research protocols. For example, if a pilot project required brain imaging at the Hoglund Brain Imaging Center, the investigator would apply to the Novel Methodology and Translational Technologies Center for funding and intellectual support. In addition we plan to establish four important committees that will bring in partners from the external scientific community, the regional academic centers, the private sector, and lay community organizations and institutions.

Through the CTSA planning process, we plan to visit one or more academic health centers who successfully obtained a full CTSA during 
the first one or two rounds of funding. In addition, our External Scientific Advisory Committee will serve as a sounding board for ideas and proposals that are generated through the planning process.

We are excited that the new clinical and translational science award can indeed provide the resources that could medically advance the clinical research agenda at KU Medical Center and throughout our region. We are confident that through the CTSA planning process we will create a blueprint for this transformative process that will allow us to join the front ranks of institutions with vibrant clinical research programs.

1. Zerhouni, E.A. Translational and Clinical Science, Time for a New Vision, New England Journal of Medicine, 353(15):1621-1623.

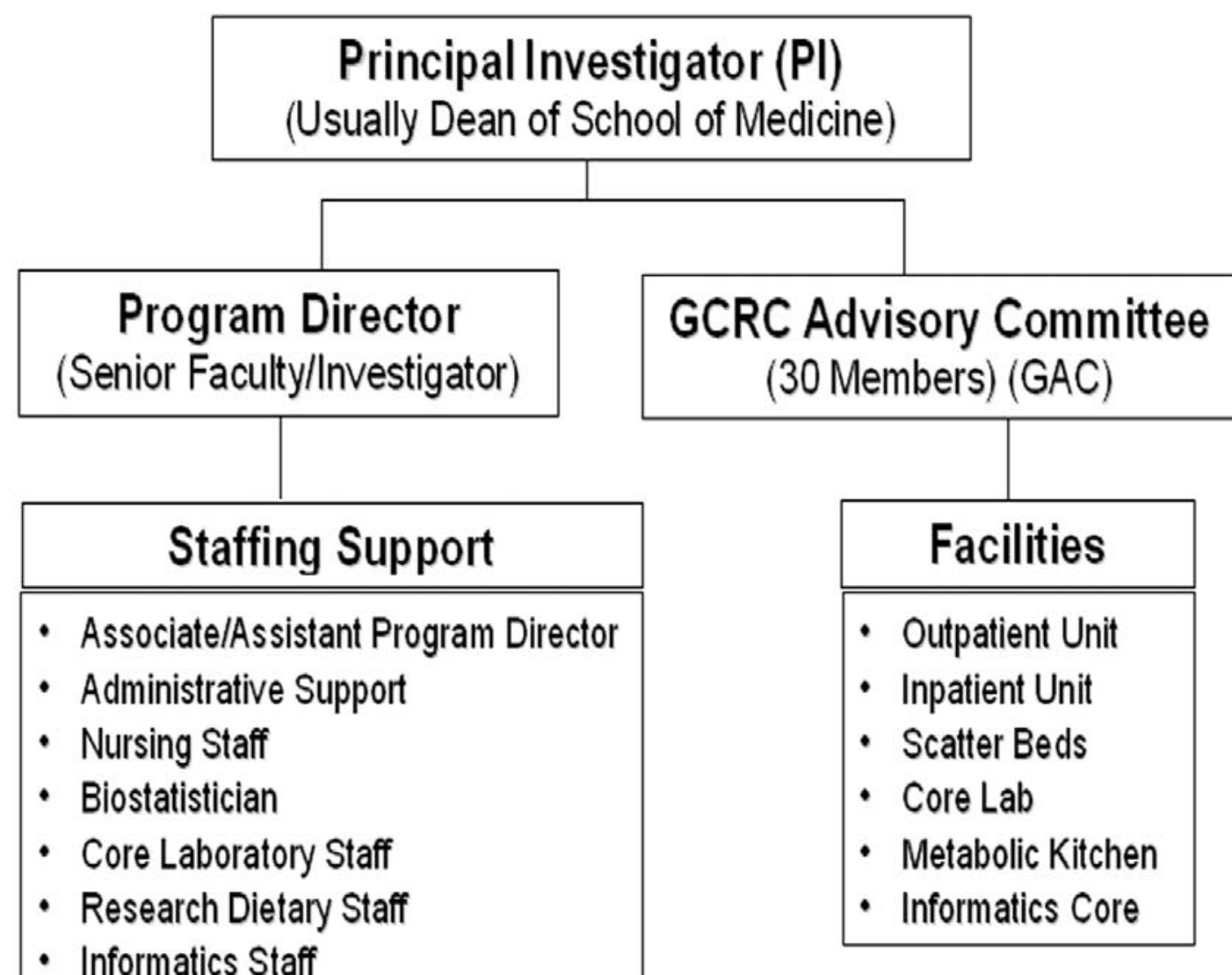




\section{Conceptual Proposal for the Heartland Institute for Clinical Research (HICR)}

An Integrated Home for Clinical and Translational Research
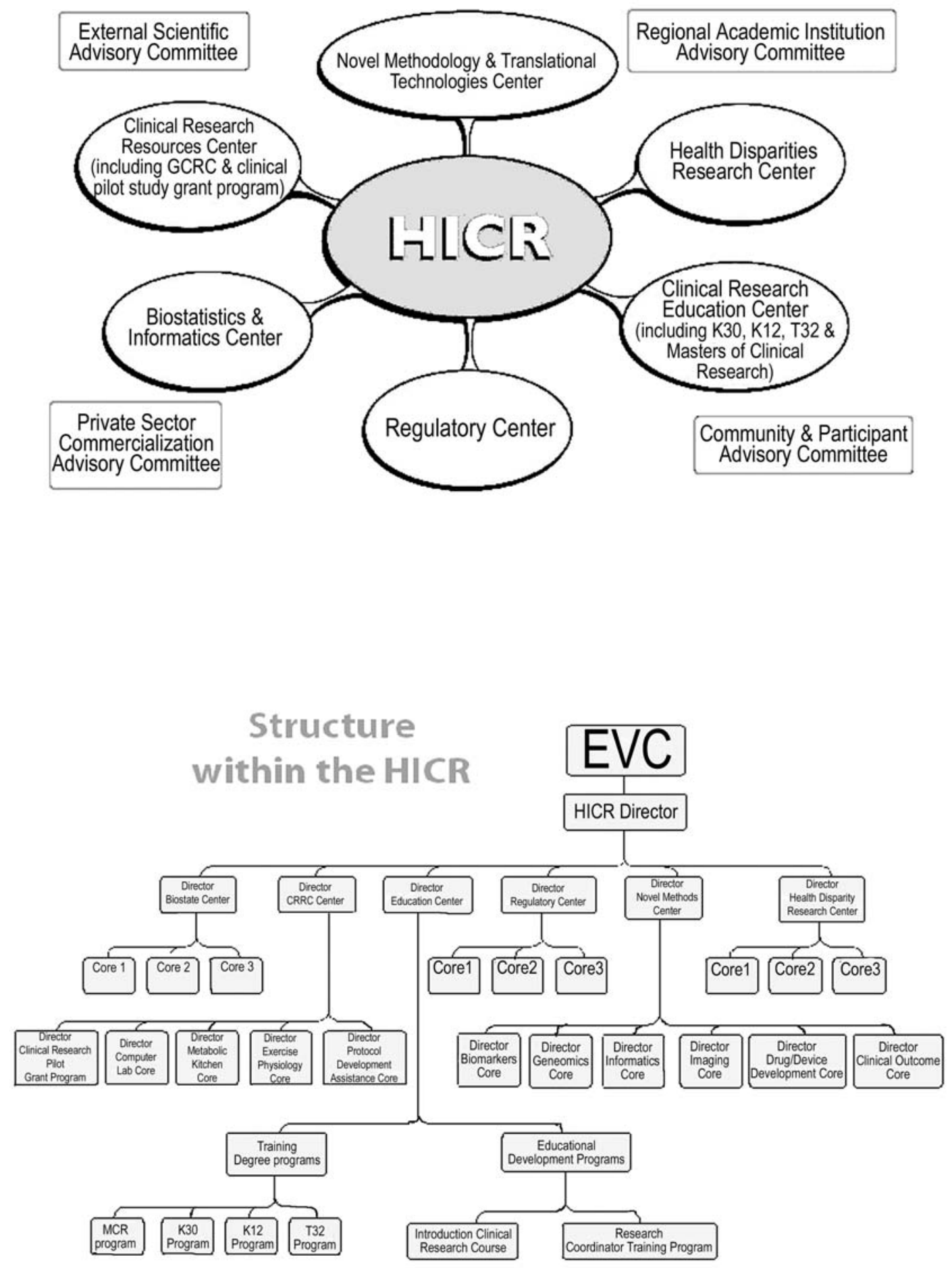


\section{CTSA Planning Committees and Sub-Committees}

\begin{tabular}{|c|c|c|}
\hline CTSA COMMITTEE & CHAIR(S) & PURPOSE \\
\hline Planning Steering Committee & $\begin{array}{l}\text { Barbara Atkinson, MD } \\
\text { Richard Barohn, MD }\end{array}$ & $\begin{array}{l}\text { Direct and oversee entire planning } \\
\text { process }\end{array}$ \\
\hline Governance Planning Sub-Committee & $\begin{array}{l}\text { Richard Barohn, MD } \\
\text { Barbara Atkinson, MD }\end{array}$ & $\begin{array}{l}\text { Develop and propose overall } \\
\text { governance and structure of } \mathrm{HICR}\end{array}$ \\
\hline Grant Writing Planning Sub-Committee & $\begin{array}{l}\text { Richard Barohn, MD } \\
\text { Lauren Aaronson, PhD, RN }\end{array}$ & Write the full NIH CTSA application \\
\hline Education Planning & Ed Ellerbeck, MD, MPH & $\begin{array}{l}\text { Develop } \mathrm{K}-12 \text { and } \mathrm{T}-32 \text { training } \\
\text { programs for the full CTSA application; } \\
\text { propose mechanisms to coordinate and } \\
\text { incorporate existing training programs } \\
\text { (e.g., K30, other T32s) }\end{array}$ \\
\hline Clinical Research Resources Planning & Richard Barohn, MD & $\begin{array}{l}\text { Expand current GCRC to include } \\
\text { additional service resources for } \\
\text { investigators (e.g., protocol } \\
\text { development, peer review assistance, } \\
\text { pilot grant program); create new Clinical } \\
\text { Research Resource Center (CRRC) }\end{array}$ \\
\hline Clinical Pilots Planning Sub-Committee & $\begin{array}{l}\text { John Ferraro, PhD } \\
\text { Ted Knous, PhD }\end{array}$ & $\begin{array}{l}\text { Create policies \& procedures for support } \\
\text { of clinical \& pilot studies in priority areas } \\
\text { within the CRRC }\end{array}$ \\
\hline Biostatistics \& Informatics Planning & Matt Mayo, PhD & $\begin{array}{l}\text { Design expanded infrastructure and } \\
\text { procedures for biostatistician and } \\
\text { informatics support }\end{array}$ \\
\hline Regulatory Planning & $\begin{array}{l}\text { Jim Voogt, PhD } \\
\text { John Finley, JD }\end{array}$ & $\begin{array}{l}\text { Develop mechanisms to support } \\
\begin{array}{l}\text { investigators with regulatory } \\
\text { requirements }\end{array}\end{array}$ \\
\hline $\begin{array}{l}\text { Novel Methods \& Translational } \\
\text { Technologies Planning }\end{array}$ & $\begin{array}{l}\text { Curt Hagedorn, MD } \\
\text { Paul Terranova, PhD }\end{array}$ & $\begin{array}{l}\text { Coordinate use of technologies } \\
\text { applicable to clinical research and } \\
\text { propose new methodologies }\end{array}$ \\
\hline Health Disparities Research Planning & $\begin{array}{l}\text { Patricia Thomas, MD } \\
\text { Kirby Randolph, PhD }\end{array}$ & $\begin{array}{l}\text { Design Health Disparities Research } \\
\text { Center with resources and services to } \\
\text { integrate disparities issues in all clinical } \\
\text { research }\end{array}$ \\
\hline Community \& Participant Planning & $\begin{array}{l}\text { Joshua Freeman, MD } \\
\text { Lauren Aaronson, PhD, RN }\end{array}$ & $\begin{array}{l}\text { Create policies and procedures for } \\
\text { provider and study participant } \\
\text { involvement in the HICR and } \\
\text { mechanisms for regular communication }\end{array}$ \\
\hline Regional Academic Institution Planning & Jim Voogt, PhD & $\begin{array}{l}\text { Develop formal partnership agreements } \\
\text { with current partners and explore } \\
\text { inclusion of other institutions from the KC } \\
\text { area }\end{array}$ \\
\hline Private Sector Commercialization Planning & $\begin{array}{r}\text { Scott Weir, PhD } \\
59\end{array}$ & $\begin{array}{l}\text { Identify opportunities for clinical \& } \\
\text { translational research with private } \\
\text { industry }\end{array}$ \\
\hline
\end{tabular}

